\title{
Considerações sobre a implementação de uma interven- ção de índole dialógica com crianças do ensino funda-
}

\section{mental}

* Stela Marques

** Regina Helena Campos

\begin{abstract}
RESUMO
Este texto apresenta um estudo ${ }^{1}$ realizado em duas escolas de ensino fundamental de Belo Horizonte. Em cada escola participaram do estudo uma turma do $5^{\circ}$ ano, considerada mais agitada, e uma de suas professoras. 0 estudo consistiu na implementação de uma intervenção de carácter dialógico e filosófico em sessões inspiradas no programa Filosofia para Crianças, que notadamente melhora o pensamento, habilidades de comunicação e competência social. Pretendeu-se observar se a intervenção tinha algum impacto na atitude agitada dos alunos. Foram recolhidos dados por meio de observações e questionários antes e depois da intervenção. Os resultados foram comparados e analisados sob quatro ângulos: disciplina, autoestima, criatividade e opinião sobre aprender a pensar bem. Apenas a avaliação da criatividade
\end{abstract} mostrou mudança negativa. Considerando o debate uma ferramenta pedagógica poderosa, cogita-se sobre o aumento da sua utilização em sala de aula e seu impacto na socialização e comunicação e possíveis consequências para o rendimento escolar.

Palavras-chave: Intervenção dialógica. Diálogo socrático. Filosofia. Debate. Metacognição. Aprender a pensar.

\begin{abstract}
This paper presents the results of a study conducted in two primary schools in Belo Horizonte, Brazil. In each school, one $5^{\text {th }}$ grade class behaviourally challenging and one of its teachers participated in the study. Its aim was to involve pupils in a dialogic intervention, in sessions inspired in the Philosophy for Children programme, which knowingly boosts thinking, communication and social skills. We wanted to observe pupils' response and ascertain whether the intervention changed their attitude of indiscipline. Data was collected through observations and before-and-after the intervention questionnaires. Results were compared and analysed under four parameters: discipline, self-esteem, creativity and opinions on learning to think better. All aspects showed improvement, except the evaluation of creativity. Considering that debates are powerful pedagogical tools, a discussion is presented involving a more prominent use of debate in the classroom, its contribution to the improvement of social and communication skills and possible impact on school attainment.
\end{abstract}

Keywords: Dialogic intervention. Socratic dialogue. Philosophy. Debate. Metacognition. Learning to think. 


\section{INTRODUÇÃO}

Este trabalho apresenta um relato de uma pesquisa realizada em duas escolas públicas do ensino fundamental de Belo Horizonte. As turmas foram selecionadas pelas coordenações das respectivas escolas por apresentar, em termos gerais, desafios de comportamento em sala de aula que eram uma fonte de desconforto e conflitos escolares. Além dos alunos dessas duas turmas, uma professora de cada turma também contribuiu para o estudo.

O estudo propôs a implementação de uma intervenção de carácter dialógico filosófico, inspirada no programa FPC, em sessões de debate de 50 minutos para pequenos grupos de alunos retirados da sala de aula ao longo de aproximadamente nove semanas. Não foi aplicada a metodologia exata das sessões do programa FPC nem os textos de debate propostos por Lipman, Sharp e Oscanyan (1980). Todavia, esse programa forneceu a base para a criação de uma dinâmica de comunidade de investigação, um espaço propício à discussão, à reflexão, ou seja, ao pensamento filosófico. A proposta foi motivada pela confiança nos benefícios do debate para o desenvolvimento do pensamento, das habilidades sociais e de comunicação, algo que poderia favorecer alunos que enfrentavam desafios em termos de comportamento escolar. Por seu turno, acreditamos que uma melhoria de atitude em sala de aula nas turmas participantes teria um impacto positivo a posteriori no processo ensino-aprendizagem.

Relativamente ao programa FPC, ele é utilizado hoje em mais de 50 países, incluindo o Brasil. Essa intervenção inspirou e interessou ao presente estudo porque visa primariamente estimular o raciocínio por meio do diálogo socrático ou filosófico e de exercícios críticos e criativos em comunidade de investigação. A intervenção define-se como um grupo de alunos reunidos para discutir assuntos pertinentes aos seus interesses, compartilhar opiniões, analisar questões, desafiar-se mutuamente, auxiliar-se na busca de razões e identificar as suposições de cada um. A implementação de uma pedagogia de cooperação, composta por relações dialógicas (a priori não críticas), fomenta sentimentos de empatia entre pares, autonomia intelectual, moral e afetiva de consequências positivas generalizadas. Propicia ainda melhorias, entre outras, do desempenho escolar, da autoestima e de valores ligados à consciência da cidadania (LELEUX, 2008). Importa, então, cogitar sobre os motivos que impedem que essa seja uma pedagogia com maior destaque em todas as salas de aula. 
Vale destacar a formação específica da pesquisadora Stela Marques, que realizou o trabalho de campo deste estudo, e que possibilitou a adaptação do material usado na pesquisa com base em seus conhecimentos no programa FPC. Em 2002, ela obteve o Philosophy for Children Level 1 Certificate, da Society for the Advancement of Philosophical Enquiry and Reflection in Education (SAPERE) $^{2}$, organização educacional do Reino Unido, fundada em 1992, que se dedica à promoção da FPC nas escolas de todo o país; a elevar os níveis de sucesso educacional por meio da inquirição filosófica; ao desenvolvimento, oferta e validação de cursos de formação; ao apoio de uma comunidade nacional de professores, formadores e escolas; à angariação de fundos para projetos e gerência de projetos de FPC; à conscientização por meio de conferências e cursos de formação; e à organização de uma publicação quadrimestral com pesquisas sobre os benefícios da FPC. Em suma, sua missão é o treinamento de professores em FPC, de forma a poderem encorajar as crianças a pensar crítica, criativa, colaborativa e afetivamente. Além disso, visa ajudar crianças, particularmente aquelas que enfrentam desvantagens, a se tornarem eternos aprendizes.

O Level 1 Certificate obtido pela pesquisadora Stela Marques significa que o curso que ela frequentou tinha e ainda tem hoje variados e específicos benefícios:

a) para professores: podem começar de imediato a facilitar inquirições de FPC na sua sala de aula;

b) para os alunos: FPC acelera o seu progresso educacional, bem como o desenvolvimento pessoal e social;

c) para diretores de escola: FPC aumenta o envolvimento dos alunos e a motivação dos professores.

Assim sendo, a pesquisadora certificada sentiu-se segura para buscar inspiração na metodologia do programa de FPC para delinear a presente pesquisa, sem, no entanto, fazer uso restrito da mesma e dos materiais proposto por Lipman, Sharp e Oscanyan (1980). Todavia, considerou-se pertinente explicar no ponto 2. a lógica do programa de FPC para ilustrar e enquadrar o leitor na modalidade, para que possa posteriormente compreender a dinâmica da pesquisa aqui apresentada.

A coleta de dados, por meio de observações e questionários, ocorreu imediatamente antes e depois da implementação da intervenção nas turmas. Os 
dados foram comparados e analisados tendo em conta as mudanças provocadas pela intervenção sobre os alunos nas seguintes vertentes: postura disciplinar dos alunos, autoestima, criatividade e sua visão sobre aprender a pensar bem.

O primeiro aspecto refere-se aos possíveis traços de indisciplina como agressividade, violência e desrespeito por outros elementos na escola. O segundo incidiu sobre a visão avaliativa global que cada indivíduo tinha de si mesmo e a possível ligação desta com a atitude de indisciplina da turma. O terceiro aspecto focou a capacidade criativa e imaginação dos alunos para a criação de um texto a partir de imagens e palavras. Pretendeu-se ainda anotar a visão dos alunos sobre as vantagens de aprender a pensar bem, isto é, a importância do pensar de forma mais eficaz e coerente. Apesar do tempo limitado disponível à pesquisa, foi possível observar melhorias, com exceção da avaliação da criatividade que, acredita-se, necessitaria de mais tempo para se desenvolver.

Este artigo apresenta uma proposta que pode auxiliar professores no manejo da discussão em sala de aula e na moderação da aprendizagem. Pretende contribuir para a promoção do debate e da aprendizagem cooperada, com vistas a melhorar as experiências de ensino e aprendizagem. Reflete sobre a importância da criação de um ambiente educacional seguro, inclusivo e democrático e seu contributo para o estímulo da autoestima, da motivação e da participação. Cogita-se, ainda, sobre alternativas de implementação que possam surtir maior impacto nos alunos em implementações futuras.

\section{CONTEXTUALIZAÇÃO TEÓRICA}

2.1. A comunidade de investigação: implicações educativas do diálogo socrático

Tradicionalmente, filosofia não se encontra entre os assuntos abordados durante a educação infantil e ensino fundamental. Em muitos países, a filosofia só entra no currículo a partir do ensino médio, o que pode sugerir que não é uma disciplina adequada para crianças. Na verdade, o pensamento filosófico requer um apurado desenvolvimento cognitivo que pode estar além do pensamento de um pré-adolescente. Porém, a abordagem de FPC (LIPMAN; SHARP; OSCANYAN, 1980) não exige como pré-requisito avançada destreza cognitiva. Defende, sim, o desenvolvimento contínuo e gradual do raciocínio e sugere que quanto mais cedo uma criança for exposta a esse estímulo, mais sólidos e duradouros são os 
resultados e o desempenho dessa criança. 0 desenvolvimento cognitivo propositado da criança pequena visa aproveitar o ímpeto do seu crescimento global para firmar valores, atitudes e hábitos benéficos à sua conduta intelectual e social futura.

A FPC é uma ferramenta pedagógica de pedigree acadêmico e prático considerável, cujo impacto positivo é abonado por um crescente número de estudos (BARROW, 2010; LELEUX, 2008). Essa metodologia idealizada por Lipman, Sharp e Oscanyan (1980) foi elaborada com base nas conclusões teóricas de Vygotsky, Dewey, Mead e Piaget e caracteriza-se pelo recurso a uma pedagogia denominada comunidade de investigação com raízes na tradição do diálogo socrático. Essa estratégia educativa fundamenta-se no pressuposto de que comunidades colaborativas e deliberativas possuem a capacidade excepcional de fomentar os pensamentos crítico, criativo e cívico, conduzindo a raciocínios, entendimentos e ajuizamentos gradualmente mais consistentes (LIPMAN, 1998).

A preocupação com o pensamento e a acuidade crítica do Homem não é uma inquietação moderna. Desde a Antiguidade Clássica que o Homem se debruça sobre si mesmo e busca entender o mundo que tanto o intriga. Esse desassossego, aliado a uma curiosidade inata, leva o sujeito a encetar uma jornada de descoberta de saberes que subsidiem a sua concepção do mundo. Cogitar sobre o melhoramento do pensamento faz parte desse percurso.

Uma ilustração evidente dessa busca são as contribuições do filósofo grego Sócrates para a educação, que são várias, embora nem sempre evidentes. Com o objetivo de tornar os cidadãos melhores, Sócrates defendia que os indivíduos deviam atuar em função de valores. Com base no antigo preceito conhece-te a ti mesmo, podemos empregar o ímpeto da tomada de consciência para fazer surgir novas atitudes benéficas para toda a sociedade. 0 cerne do método socrático é o diálogo. No diálogo socrático não tratamos com um mestre que comunica qualquer coisa a um aluno, mas sim, indivíduos que comunicam entre si por meio de uma sucessão de interrogações. Pelo diálogo, Sócrates pretendia destruir o mestre no discípulo (que sabe tudo) para lhe incutir o desejo de um verdadeiro mestrado interior, levando-o à autonomia que só o conhece-te a ti próprio lhe podia conferir.

Fundamentalmente, o sucesso educativo da abordagem de FPC depende da qualidade cognitiva da discussão em sala de aula. Uma conversação é uma forma relativamente inócua de discussão. Uma conversa geralmente exige um 
baixo nível de raciocínio ou investigação e, no que respeita à reflexão, esta pode ser insuficiente ou superficial. Já um diálogo pode ser visto como uma inquirição deliberada, um raciocínio compartilhado, por conter um esforço definido de exploração cognitiva, juntamente com tomadas de raciocínio complexas e específicas. Para Lipman, a educação como forma de inquirição deve começar com algo que os alunos consideram problemático, seguido de um desenvolvimento analítico baseado no que eles consideram interessante, intrigante ou importante (LIPMAN, 1998).

Nesse sentido, o diálogo filosófico é uma prática de pensamento crítico, que apoia e contribui para a edificação de uma comunidade de investigação pensante, que possibilita o surgimento de características genéricas essenciais a um indivíduo bem preparado. Como já foi explicado, não se discute aqui o estabelecimento de uma mera conversa, mas sim, o fomento de uma discussão com fins claramente definidos, que possibilita a reflexão crítica de um assunto. Perante a onipresença da reflexão não-crítica na sala de aula, Matthew Lipman apela ao ensino de filosofia e sua integração nos programas do ensino fundamental e médio para permitir o desenvolvimento da reflexão crítica, que é "um modo de reflexão autocorretiva, permeável ao contexto e apoiada em critérios em vista de emitir julgamentos" (LIPMAN, 2008, p. 29).

É possível ainda analisar a relevância da discussão segundo a perspectiva piagetiana, que defende a discussão e o diálogo na escola como ferramentas essenciais para a construção do pensamento e da socialização. Para Piaget, a criança é uma fonte de conhecimento e não um mero receptáculo vazio; é alguém que inventa os instrumentos do seu conhecimento e os aplica para criar novos conteúdos perante novas possibilidades. Compete à educação conduzir e provocar a criança na sua busca de novos conteúdos e da criatividade. Como explica Parrat-Dayan (2007), Piaget considerava a discussão como um dos elementos que permitem evoluir do egocentrismo, característico da mentalidade infantil, para a descentração. A discussão veicula o estímulo da criatividade, do sentido crítico e possibilita a confrontação de opiniões divergentes. Mais, a discussão é o elemento-chave de uma pedagogia que respeita o direito de expressão de ideias num espaço coletivo e público, onde se aceita o pluralismo. Para tal, deve permitir o desenvolvimento do pensamento da criança, da cidadania e da democracia. Isso coloca em destaque o papel do ensino. É pela educação e pela construção do pensamento que é possível conduzir as crianças à elaboração da personalidade. A difusão e o progresso do saber processam-se por meio da interação dos indivíduos, numa ação transitiva recíproca entre pares. Esse é 
o âmago da discussão e do diálogo em sala de aula.

Num movimento sistêmico contínuo, salienta-se ainda o papel do professor como aquele que apresenta desafios, que provoca a curiosidade dos alunos e que os incita a buscar respostas. Como sugere Berbel (1998, p. 32), "a partir de um problema, busca-se compreendê-lo, fundamentá-lo, buscam-se dados para isso, que são analisados e discutidos; por último, são elaboradas hipóteses de solução, que devem ser colocadas em prática para serem comprovadas e validadas." Dessa forma, a comunidade de investigação encoraja a independência cognitiva ao mesmo tempo em que incita a interação entre seus membros. Reflexão e debate contínuos podem resultar na construção colaborativa de novos significados. A mediação dos processos sociais e cognitivos por parte do professor também contribui para a compreensão de significados e melhores resultados de aprendizagem.

2.2 Pressupostos pedagógicos e filosóficos da Filosofia para Crianças e postulados construtivistas implícitos nesta proposta educativa

Examinar os pressupostos filosóficos e pedagógicos de Lipman equivale a estudar a filosofia da educação pragmatista e as teses da epistemologia construtivista que nela estão implícitas (DANIEL, 2000). Importa, antes, situar a abordagem de FPC no continuum das práticas como uma pedagogia inspirada no pragmatismo e no socioconstrutivismo, que se fundamenta na filosofia da educação pragmatista que entende o aluno como um "sujeito", ou seja, alguém ancorado a uma sociedade e titular de uma consciência pessoal a social. Tais perspectivas defendem que a educação deve servir para melhorar a sociedade. Mas os objetivos da educação vão além da iniciação dos jovens nas normas, leis e tradições da sua cultura. Como endossado por Freire (1970), devem também possibilitar a apropriação dessa cultura de uma maneira crítica. Isso só acontece quando reconhecerem o caráter social e construído do saber científico que substitui, por exemplo, a verdade pela viabilidade. Sob o ponto de vista heurístico, pressupõe-se que a finalidade do ensino é estimular o questionamento nos alunos. O saber passa a ser algo significativo e contextual, isto é, ele faz parte da reflexão e do diálogo gerado numa comunidade de pares para provocar a reconstrução social. Desse modo, a escola forma sujeitos ativos, capazes de edificar seu sistema de interpretação e sua representação do mundo, e estes, 
por seu turno, vão gerar condições favoráveis à cooperação, à emancipação e à democratização (DEWEY, 1963).

Neste contexto, o pensamento crítico é a práxis por meio da qual ele estabelece uma relação entre a reflexão e a ação. A aprendizagem do pensamento crítico é um processo, não um produto, e tem por objetivo a concepção de uma consciência crítica capaz de conduzir à emancipação e à autonomia do indivíduo e da comunidade (FREIRE, 1970). Essa aprendizagem visa aperfeiçoar a experiência individual e social que advém do conhecimento construído pelos alunos, mais do aquele transmitido pelo professor. 0 pensamento crítico pressupõe, não só um saber-fazer e um saber-dizer, mas também um saber-viver junto (DELORS, 1996).

Quanto aos postulados construtivistas implícitos na FPC, parte-se do pressuposto de que as teorias construtivistas decorrem da epistemologia e não da pedagogia, já que pretendem clarificar o que se conhece e como se conhece (GLASERSFELD, 1998). Por conseguinte, o construtivismo delineia princípios epistemológicos que são aproveitados e empregues no âmbito da educação. É com base nesse pressuposto que se discutem três postulados construtivistas que estão estreitamente relacionados com esta abordagem.

O primeiro postulado aponta para o caráter construído dos conhecimentos. Defende que o saber não é uma realidade objetiva, predeterminada fora do sujeito, pelo contrário, é uma construção do sujeito que busca o saber (DEWEY, 1963), ou seja, o saber não está pronto para ser consumido fora de nós, tem que ser construído. Isso significa que a realidade só existe no sujeito, é dependente dele e deve ser construída e não descoberta. Ela obriga o sujeito a descartar uma atitude de mero receptor para assumir uma atitude de busca mais ativa. A aplicação desse postulado na educação conduz a três consequências: a responsabilização do aluno, seu envolvimento no processo conjunto de geração do saber e, por consequência, o desenvolvimento da autoestima (DANIEL; SCHLEIFER, 2008).

O segundo postulado defende o caráter viável dos conhecimentos ou contextualização, e assim, contrapõe-se à noção de verdade. De acordo com os pragmatistas e os construtivistas, a verdade nunca é final. É um processo aberto e interminável por estar relacionado às normas vigentes e aceitas num dado momento e aos critérios estabelecidos por um grupo, cultura ou sociedade, ou seja, uma verdade é aceita ou rejeitada consoante as interpretações, interes- 
ses e justificativas de quadros teóricos de diferentes grupos ou comunidades. Para contornar essa situação, os construtivistas optaram pela viabilidade dos conhecimentos, que se refere à busca por explicações e interpretações viáveis do funcionamento do mundo. Os pragmatistas complementam essa ideia com a contextualização, que defende que essas explicações e interpretações são o resultado de um ajustamento ligado ao contexto e que procede da experiência pessoal. Dessa forma, a viabilidade ou a contextualização dos conhecimentos envolvem uma multiplicidade de explicações fundamentadas e justificadas. Além disso, valorizam a partilha entre pares por entender que os conhecimentos construídos só são validados e considerados verdadeiros quando são justificados experimental e teoricamente e depois reafirmados por vários sujeitos (MEAD, 1972). Em educação, o que determina a validade dos conhecimentos construídos pelos alunos é a sua viabilidade e não a sua correlação com saberes científicos já instituídos. Daí ser importante incentivar, ou melhor, incutir nos alunos o hábito de experimentar, justificar e confrontar suas ideias e conhecimentos.

O terceiro postulado põe em relevo o caráter social do processo de produção de conhecimentos. Entra-se, assim, no domínio do socioconstrutivismo. Embasado nos princípios teóricos de Vygotsky (1985), defende que os indivíduos constroem o conhecimento devido à linguagem e à interação social. Ou seja, os processos sociocognitivos desenvolvem-se a partir da estimulação das habilidades de pensamento complexo que se amplificam devido às relações que o indivíduo mantem com o seu meio. Em suma, as interações sociais são essenciais ao desenvolvimento cognitivo, tanto quanto a própria linguagem, e a complexificação do processo de construção de conhecimentos não pode ocorrer sem as interações, sobretudo linguísticas, dos sujeitos (MEAD, 1972). Dessa forma, esse postulado destaca a importância da interação no processo de produção de conhecimentos, levando o aluno a transpor a pura memorização para se envolver com um processo de busca consciente e espontânea com seus pares. Por outro lado, o confronto e discrepância de opiniões entre pares geram conflitos cognitivos cruciais, pois levam o aluno a: questionar-se, duvidar, problematizar a realidade, sugerir alternativas de soluções, criticar as alternativas apresentadas e identificar critérios para encontrar a mais lógica e, ainda, aplicar a solução escolhida à experiência cotidiana. Além disso, tal postulado realça a complexidade da reflexão dos alunos, associada normalmente ao pensamento crítico, sem o qual o conhecimento pode ser substituído por um relativismo negativo, campo fértil para o preconceito, a desconfiança e a utopia.

Portanto, é à luz desse enquadramento teórico que os dados apresentados 
a seguir foram analisados.

\section{METODOLOGIA}

A análise de dados foi conduzida com base no estudo etnográfico da intervenção em duas escolas do ensino fundamental públicas de Belo Horizonte. A utilização da metodologia etnográfica foi escolhida por possibilitar a geração de conceitos, construtos, teorias descritivas e explicativas que contribuem para o desenvolvimento do conhecimento básico e específico em educação (AAMODT, 1991). Assim, cada etnografia, por constituir uma descrição vivida e detalhada da realidade de pessoas pertencentes a um determinado contexto cultural, representa uma parte do conhecimento e da história da experiência proposta para a compreensão e tradução do outro.

As unidades de análise selecionadas foram duas turmas do $5^{\circ}$ ano, composta respectivamente por 17 e 18 alunos de 10 anos. Todos os alunos foram convidados a participar da pesquisa e apenas um aluno não obteve autorização de seus responsáveis educacionais para participar. As turmas foram divididas em Grupo A e Grupo B, compostos por cerca de oito alunos cada. A divisão da turma permitiu a replicação instantânea da pesquisa e a coleta de dados lícitos para comparação, já que ambos os grupos foram alvo dos mesmos procedimentos, porém, em sessões distintas.

O critério de escolha das turmas foi baseado no acentuado índice de indisciplina dos alunos reportado pelos professores, que foi considerado um parâmetro seletivo válido. Deixamos claro que o foco do programa FPC não é disciplinar alunos malcomportados, nem tampouco foi essa a lógica por trás da escolha da intervenção realizada. Pretendíamos apostar no sentido filosófico da intervenção, de forma a propiciar momentos de reflexão sobre a própria ação e estimular o debate, inclusivamente sobre comportamento.

Verifica-se que uma ampla gama de comportamentos são considerados agressivos e fontes de indisciplina, variando do exemplo extremo do ataque físico a formas mais veladas, como a maledicência. Todavia, o denominador comum desses comportamentos é a intenção de causar prejuízo ao outro, aliada à expectativa de que tal objetivo será atingido (LOEBER et al., 1998). Então, para efeitos deste estudo, foram selecionadas as turmas que, na escola, apresentava maior índice de reclamações de professores e alunos por sua atitude indiscipli- 
nada, causa direta de desconforto e atritos escolares. A indisciplina acentuada da turma serviu apenas de componente seletiva, não tendo sido possível destrinchar as variáveis biológicas, socioculturais e situacionais desencadeadoras dessa indisciplina.

O estudo também contou com a colaboração de duas professoras das turmas participantes, selecionadas pela sua disponibilidade e por ter duplo horário semanal com as turmas, o que possibilitou o trabalho com os dois grupos no mesmo dia. As professoras contribuíram para a avaliação do estudo completando questionários relativos ao perfil da turma antes e depois da implementação da intervenção.

O estudo utilizou uma abordagem de pesquisa qualitativa/interpretativa com recurso a vários métodos de recolha de dados. A coleta foi realizada antes, durante e após a implementação da intervenção e os mesmos instrumentos foram aplicados a todos os grupos de alunos. A fim de identificar mudanças provocadas pela intervenção por meio da comparação de dados, os métodos de recolha de informação utilizados na pré-avaliação foram re-aplicados na pós-avaliação, e consistiram em:

a) Observação não-participativa;

b) Questionário sobre autoestima;

c) Redação de um texto criativo.

Para as observações dos alunos em situação de sala de aula regular, foi utilizada uma grade com diversos critérios e parâmetros pertinentes à intervenção.

No respeitante ao questionário sobre autoestima, o instrumento aplicado foi o B/G-STEEM, escala primária de autoestima para crianças com itens de locus de controle, produzida no Reino Unido por Barbara Maines e George Robinson (1988). Com esse questionário pretendeu-se determinar, de forma simplificada, a opinião que os alunos tinham acerca de si mesmos, opinião esta que pode englobar o valor ou sentimento que se tem de si mesmo (amor próprio, auto-valorização) e todos os demais comportamentos e pensamentos que demonstram a confiança, segurança e valor que o indivíduo dá a si (auto-confiança), nas relações e interações com outras pessoas e com o mundo. Quanto à avaliação referente ao locus de controle, conceito que se refere às expectativas generalizadas de controlo interno e externo do indivíduo sobre uma situação 
ou reforço (ROTTER, 1990) ${ }^{3}$, ela foi desconsiderada. O estudo visava analisar somente a autoestima dos participantes, portanto, os itens do locus de controle foram descartados. As opções de resposta dos alunos eram sim e não, de uma lista de 27 questões.

Os alunos contribuíram ainda com a redação de um texto criativo. Pretendeu-se verificar o eventual impacto da intervenção sobre o poder criativo dos alunos, entendendo criatividade como algo que envolve a criação de um produto original e de valor. A tarefa consistiu na elaboração de uma pequena história a partir de três palavras dadas - floresta, caçador e urso. Foi oferecido o início da história, "Quando chegou à floresta, Paulinho..." e era pedido que o aluno continuasse conforme a sua imaginação.

Ao longo da intervenção, os alunos preencheram, no final de cada sessão, uma ficha auto-avaliativa onde anotavam dados sobre o seu comportamento durante a sessão, o que tinham aprendido e do que tinham gostado mais e menos. Esse momento de reflexão propositado visou fomentar a metacognição dos alunos, ou seja, sua capacidade de pensar sobre o pensar. A essência do processo metacognitivo está na capacidade do ser humano de ter consciência de seus atos e pensamentos. Com isso, pretendia-se estimular a capacidade dos alunos de monitorar e auto-regular os processos cognitivos (FLAVELL, 1987; STERNBERG, 2000).

No final da intervenção, os alunos ainda registraram sua opinião sobre a intervenção e sobre o impacto que aprender a pensar melhor podia ter em suas vidas.

Assim, a estratégia de recolha de informação centrou-se na observação dos alunos antes e depois da aplicação da intervenção, incluindo ainda o uso de outras técnicas, como questionários e a análise do texto criativo. 0 tratamento da informação feito após a conclusão da pesquisa envolveu a comparação e análise dos dados produzidos pelos dois grupos, que foram alvo dos mesmos métodos de recolha de dados. O tratamento da informação assentou na sua triangulação, que facilitou e fortaleceu a validação e confiabilidade dos dados recolhidos, algo fundamental a pesquisas de índole qualitativa: cruzamento das interpretações da investigadora como os dados obtidos pelos restantes instrumentos, tratados por meio da análise de conteúdo. Além disso, a combinação de várias técnicas assentes na observação e na interpretação do observador é usada e apontada como a base da estratégia etnográfica (CARIA, 2000). 


\section{A IMPLEMENTAÇÃO DA INTERVENÇÃO DIALÓGICA-FILOSÓFICA}

A seguir são apresentados os principais resultados do experimento, começando por se fazer uma breve descrição da intervenção apresentada aos alunos, passando-se, depois, à análise da questão do impacto do programa nos parâmetros analisados: disciplina, autoestima, criatividade e visão dos alunos sobre aprender a pensar bem.

\subsection{A intervenção}

As sessões seguiram um enquadramento sequencial específico. 0 trabalho de campo decorreu durante seis meses. Durante esse período de tempo, foi possível proceder à pré-avaliação, à implementação de sessões (duplicadas) de 50 minutos para cada grupo e realizar a pós-avaliação. Em cada escola, tanto o Grupo A como o Grupo B foram retirados da sua turma e participaram da sessão separadamente, numa sala que permitiu que os alunos sentassem-se em círculo. O material da intervenção oferecido ao Grupo A foi apresentado na sessão seguinte ao Grupo B, permitindo assim que os alunos de ambos os grupos fossem expostos a estímulos idênticos. 0 material consistiu de textos de conteúdo propício ao debate, com conceitos como responsabilidade, liberdade e tolerância. Conforme já foi explicado anteriormente, essa intervenção não seguiu a rigor a proposta de FPC de Lipman, buscou inspiração nesta e foi consequentemente adaptada. Por esse motivo, foi utilizado um material de leitura e reflexão diferente, mas que, todavia, foi efetivo no estímulo do debate filosófico, que era o objetivo da intervenção. Ressalta-se ainda que a escolha dos textos não teve motivação "moralizante" de alunos indisciplinados, mas sim seu potencial para estimular o debate filosófico.

Uma etapa determinante para o sucesso das sessões foi o esclarecimento das Regras de Ouro da intervenção, elaboradas em conjunto com as sugestões dos alunos, expostas num cartaz e relembradas a cada sessão para garantir o bom andamento da discussão.

A etapa central da intervenção consistiu na leitura do texto do dia. De seguida, os alunos foram convidados a refletir sobre o assunto apresentado de forma a poder elaborar uma pergunta filosófica. Foi explicado que a resposta a essa pergunta ia além do "Sim/Não" e exigia uma argumentação, por exemplo, 
"Sim, porque..." / "Não, porque..." Após a elaboração de perguntas, os alunos elegeram por votação uma delas para debater na sessão. A seguir, os alunos expuseram seus pontos de vista, trocaram ideias e discutiram tópicos que foram emergindo do assunto do dia.

No final de cada uma das sessões, os alunos preencheram uma ficha de avaliação formativa da sessão. A aplicação dessa tarefa avaliativa proporcionou a oportunidade de não só fazer o aluno refletir individualmente sobre o tópico discutido durante a sessão, mas também refletir sobre o seu desempenho nesse dia e de como este seria na sessão seguinte. A ficha apresentou várias afirmações e ofereceu três alternativas como resposta.

\subsection{Impacto da intervenção sobre disciplina}

Não é possível afirmar que o estudo implementado tenha resolvido o problema de indisciplina das turmas participantes. No entanto, apesar da curta duração da intervenção, foi possível observar uma melhoria na atitude dos alunos, não só no decorrer das sessões, bem como durante as aulas, conforme relato da uma professora participante. Inicialmente, ela havia declarado que a turma apresentava um comportamento difícil durante as aulas:

"A turma é muito agitada. Dificilmente se consegue conduzir a aula tal como planejada, devido principalmente às constantes intervenções para manter os alunos concentrados, para resolver os conflitos, para manter a participação ativa de todos".

Já no questionário que completou após o término da intervenção, a professora afirmou ter observado uma mudança de atitude em sala de aula após o envolvimento da turma com FPC:

Tive pouco tempo para perceber mudanças, porém, observei o esforço por parte de alguns alunos em controlar mais a sua fala para que ela não fosse agressiva, para que ela fosse colocada em momento oportuno, respeitando o colega que havia levantado a mão primeiro, sem interrompê-lo.

A intervenção foi implementada durante um curto período de tempo e sofreu algumas interrupções devido às atividades regulares da turma. A professora 
considerou que mudanças mais explícitas poderiam ter ocorrido caso o mesmo estudo fosse realizado por um período de tempo contínuo mais alargado:

Certamente poderíamos perceber outros e, talvez, ainda mais significativos resultados. Considero que a participação e envolvimento dos alunos na pesquisa foram um tanto quanto prejudicados pelas interrupções na sequência proposta provocadas pelas saídas programadas, confraternizações de alunos e outras atividades decididas pela escola.

Também foi observado o aumento da participação e interesse dos alunos durante as sessões. Em uma das escolas, comparativamente, o Grupo A começou por ser o mais interessado e participativo, enquanto o Grupo B demonstrava mais desconcentração, causada, sobretudo, pelas interrupções constantes de um aluno durante o debate, chegando inclusivamente a se levantar em frente ao grupo (disposto em círculo), para de seguida suspender a respiração até desmaiar. Esse aluno acabou por sair do grupo e verificou-se que a participação e interesse do grupo aumentaram.

Na nossa ótica, essas melhorias revelam o caráter estimulante da intervenção e confirmam o impacto que era esperado com a participação em sessões regulares de debate filosófico. É lícito argumentar que, por serem muito jovens, os alunos reagiram positivamente à intervenção por ser novidade e uma atividade diferente e divertida. Lipman (1994) explica que, para os alunos, a escola, no início, está cheia de sentido, mas com o passar do tempo, desaparece o encantamento, levando-os à desmotivação de participar da aula e ao estudo apenas para passar nos exames. Não surpreenderá, então, que a introdução de novidade na rotina educativa dos alunos possa ter resultado na melhoria da sua atitude escolar. 0 contato com o debate filosófico, num ambiente educativo investigativo e dialógico diferente foi um estímulo à participação, ao interesse e até à curiosidade dos alunos, uma oportunidade de descobrir e debater significados embutidos nas informações discutidas nas sessões. Mais significativo, porém, foi a observação dessa mudança de atitude durante as aulas regulares, como foi relatado pela professora da turma.

Analisar as interações sociais da comunidade de investigação, que podem possibilitar aprendizagens significativas e bem sucedidas, exige que também sejam analisados os aspectos motivacionais que permitem perceber se o aluno está disposto a dar atenção e se empenhar nas atividades propostas. Torna-se imprescindível considerar os elementos que constituem aspectos mobilizadores 
para eles. No caso da co-construção do conhecimento, a análise das interações estabelecidas é discutida no espaço da convergência e divergência em relação aos objetivos propostos que integram os aspectos intelectuais e motivacionais (BRANCO; VALSINER, 1997). A aprendizagem acontece na troca entre os atores envolvidos em um processo intersubjetivo permeado de simbolismos e significações. O aluno é ativo na elaboração dos conteúdos, cabendo ao moderador orientar o debate, aprofundando as contribuições dos alunos de forma instigadora e entusiástica.

Outro aspecto que pode ser responsável por essa mudança de atitude foi o elemento central da intervenção: o debate em grupo ou comunidade de investigação. Lembrando que não foram discutidos temas filosóficos complexos nem de índole clássica, muito pelo contrário, as discussões fluíram de textos de natureza simples e até conhecidos dos alunos (como fábulas), e foram ganhando consistência ao longo da intervenção. Essa escolha foi intencional por facilitar o primeiro contato com esse tipo de experiência e tendo em conta a idade dos participantes. Num modelo escolar em que não se estimula o diálogo e o debate, apresentar aos alunos textos para debate de teor denso poderia inviabilizar a realização da intervenção. Podemos sugerir, então, que a mudança de atitude pode ter resultado de vários fatores: a própria natureza do debate, a observância das Regras de Ouro, o estabelecimento de uma comunidade de investigação e a atuação da moderadora do debate..

$\mathrm{Na}$ verdade, todos esses fatores estão interligados e influenciaram-se mutuamente. Comecemos por analisar o papel da moderadora da intervenção. A sua responsabilidade central foi a de edificar na intervenção uma comunidade de investigação. Lipman (1995) esclarece que as deliberações feitas em comunidade de investigação não são simples conversações sobre todos e quaisquer assuntos sem um compromisso ou o objetivo final de obter uma conclusão que sirva para sua vida. Tratam-se, sim, de diálogos logicamente disciplinados, com um compromisso e o desejo de se chegar a uma conclusão ou a uma verdade. Num diálogo há troca de ideias, discordâncias, acordos de pensamento, questionamentos e avanços. O diálogo foi, então, a forma de comunicação que predominou na comunidade de investigação gerada no experimento aqui descrito, por ser uma forma pedagógica de discussão em que todos podem participar e expressar o seu pensamento. Sob a orientação da moderadora do debate, pode-se dizer que todos os alunos compreenderam o valor do enriquecimento mútuo por meio da permuta de pontos de vista. 
A discussão é um elemento essencial da pedagogia que procura desenvolver o pensamento do aluno, a cidadania e a democracia. Por outras palavras, a discussão é vital a uma educação que perfilha o direito de expressar ideias num espaço coletivo onde se valoriza o pluralismo. Como explica Parrat-Dayan (2007), o debate é constitutivo da democracia, logo, não podemos aprender a democracia se não aprendemos a discutir e, para isso, é necessário ter regras que permitam a discussão. É essencial a presença de disciplina na discussão. Sem regras, esta pode seguir múltiplos caminhos, gerar polêmicas, conflitos, violência. Assim, a elaboração e discussão prévia das Regras de Ouro da intervenção cimentaram uma plataforma de aprendizagem democrática e sistemática, importante para garantir a coerência e a ordem do debate. Só foi possível gerar uma discussão sã porque todos os envolvidos respeitaram os diferentes papéis pré-estabelecidos para a realização da confrontação regulada das ideias (como participantes e moderador) e os procedimentos pré-determinados para melhor se organizar o debate (tempo do debate, falar um aluno de cada vez, sem interromper nem ser interrompido).

Numa discussão, a linguagem e seu potencial argumentativo são usados como base para a troca. Colocam-se em evidência afirmações e contradições, cujos argumentos geram novas ideias, renovam posicionamentos e direcionam o indivíduo para a objetividade. Nas sessões iniciais da intervenção, todos os alunos, sem experiência prévia em debater suas ideias em grupo, limitaram-se a partilhar experiências próprias. No decorrer da intervenção, porém, a maioria conseguiu aprimorar o seu potencial argumentativo e aprofundar suas justificações. Essa constatação destaca o poder da aprendizagem coletiva, num ambiente seguro e com a orientação afável de um moderador. Discutir e pensar em conjunto favoreceu a solidariedade e a entreajuda. Por um lado, cada aluno pôde contribuir para a compreensão pessoal e do grupo com a exposição da sua interpretação particular; por outro lado, o grupo permitiu o enriquecimento geral por meio da partilha das diferentes perspectivas, ideias e conhecimentos.

Pela estimulação do debate, os alunos puderam experimentar a importância do respeito verbal e não-verbal pelo outro, a importância da tolerância pelas opiniões do outro, em suma, a importância da compreensão e de permitir que o grupo reformulasse argumentos individuais. É o conflito cognitivo provocado pela diversidade de pontos de vista entre pares que permite que os alunos questionem-se, duvidem, problematizem a realidade, proponham soluções, critiquem as alternativas sugeridas e identifiquem os critérios para achar a solução mais coerente. Em última instância, permite aplicar a solução escolhida na ex- 
periência cotidiana, revelando a complexidade da reflexão dos alunos e de seu pensamento crítico.

Também distintivo da comunidade de investigação é o fato de que todos merecem ser incluídos no debate e ser respeitados, o que torna todas as contribuições válidas para a discussão. Foi com a contribuição de todos que se puderam alcançar os objetivos da comunidade de investigação: um produto. Para Lipman (1995, p. 196), esse produto é "o despertar nas crianças a capacidade de investigar sempre, buscando compreender o mundo em que vivem com criticidade, reflexão e o pensar melhor". Esse autor defende ainda que, para se chegar a esse produto, é necessário permanecer na investigação e seguir o argumento por onde ele for, fazendo sempre perguntas, pois elas incitam o indivíduo a pensar de maneira diferente. Da mesma forma que as nossas experiências ocorrem em circunstâncias que envolvem ação e reação, também a investigação acontece em situações concretas, numa comunidade que compartilha, que dialoga e que lança perguntas e afirmações.

\subsection{Impacto da intervenção sobre a autoestima}

Como já foi explicado anteriormente, as turmas participantes apresentavam acentuado nível de indisciplina, o que poderia levar a pressupor que comportamentos inadequados eram causados por baixa autoestima. Ora, os dados coletados na pré-avaliação não indicaram autoestima baixa acentuada em nenhum dos grupos de alunos. Os dados dos questionários são dados numa escala de 0 a 20 valores (de baixa para alta autoestima).

Nos pré-testes, ficou claro que a maioria dos alunos de todos os grupos possuía boa autoestima e os valores que se mantiveram na pós-avaliação. Em uma escola, apenas um evidenciou baixa autoestima antes da intervenção $(6 / 20)$, melhorando na pós-avaliação (17/20). A pós-avaliação mostrou que dois alunos desceram seus níveis de autoestima, sem, no entanto, representar uma descida drástica, 15/20 para 13/20 e 16/20 para 15/20.

$\mathrm{Na}$ outra escola, ficou claro o elevado nível de autoestima dos alunos na pré-avaliação. Três alunos mantiveram seus valores altos, 20/20, 19/20 e $17 / 20$, enquanto outros melhoraram seus valores iniciais, passando de $16 / 20$ para 19/20 e 18/20 para 20/20, por exemplo. Dados da pós-avaliação mostra- 
ram que os valores de três alunos desceram: 20/20 para 18/20 e 20/20 para $19 / 20$, ainda assim, valores que permaneceram elevados; e 19/20 para 15/20, sendo esta a descida mais significativa.

$\mathrm{Na}$ opinião de uma das professoras participantes, o envolvimento dos alunos com a intervenção foi importante, pois permitiu que os alunos desenvolvessem habilidades que favorecem o rendimento em sala de aula: $v$

Considero que a intervenção é muito positiva uma vez que pode trazer benefícios principalmente no que diz respeito à forma como o aluno participa das aulas (aumento da concentração, da autoestima, da autoconfiança). Porém talvez seja necessário o desenvolvimento de um trabalho por um maior tempo, a fim de explorar melhor as potencialidades do que é desenvolvido.

Existem vários estudos que ligam autoestima com cognição, emoção e comportamento. A maioria dos resultados indica que autoestima elevada está relacionada com aspectos positivos como otimismo, emoções positivas e até saúde física (MYERS; DIENER, 1995), enquanto que autoestima baixa está ligada a aspectos negativos ou indesejáveis como depressão, medo, timidez ou solidão (PHILPOT; HOLLIMAN; MADONNA, 1995). Há também quem defenda que agressividade e comportamento violento estão relacionados com autoestima elevada (BAUMEISTER et al., 2003). Comportamento agressivo, como iniciar uma briga, é um comportamento arriscado, que requer coragem e confiança nas próprias habilidades para vencer o oponente. Por isso, a procura de situações de risco é normalmente considerada algo típico de indivíduos com alta autoestima (SPENCER; JOSEPHS; STEELE, 1993). Por seu lado, indivíduos com baixa autoestima apresentam falta de confiança nas suas habilidades - normalmente esperam fracassar em situações de risco ou de desafio, logo, evitam o confronto (TICE, 1993).

As posições teóricas são variadas. Por muito tempo, a agressividade foi ligada à baixa autoestima, outras formulações teóricas vincularam comportamento hostil, indisciplina ou agressividade tanto à autoestima elevada como reduzida. Intuitivamente, parece difícil aceitar que um indivíduo que se sente bem consigo mesmo possa ser agressivo com os outros. Isto pode sugerir que, apesar da superfície autoconfiante e auto-avaliações que indicam autoestima elevada, na verdade, esses indivíduos acobertam inseguranças em relação à sua auto visão. No estudo aqui apresentado, o questionário de autoestima indicou um nível de autoestima inicial elevado. Todavia, pelo próprio instrumento utilizado, dados coletados e curta duração da intervenção, não foi possível 
determinar ou medir as causas (positivas ou negativas) desse nível elevado de autoestima nem confirmar se a melhora registrada no final da implementação foi causa direta do estudo.

Não obstante, é possível afirmar que a melhora da autoestima observada após a intervenção põe em evidência a capacidade da intervenção de influenciar positivamente a componente emocional dos alunos. Analisando o potencial da intervenção, tanto como mecanismo dialógico como participativo, podemos deduzir que o estímulo à participação ordenada, democrática e inclusiva favorece o bem-estar do grupo. Participantes mais e menos confiantes participam do debate no mesmo pé de igualdade, sem sofrer descriminação, crítica ou escárnio pelos seus pontos de vista. Isto é facilitado pela conduta de tolerância e entusiasmo do moderador. Cabe-lhe a responsabilidade de estabelecer um ambiente de aprendizagem seguro, respeitoso e afável, onde é empolgante aprender e participar. Gradualmente, o aluno com baixa autoestima, percebendo que é seguro partilhar a sua opinião, acaba por assumir uma atitude menos defensiva e mais dinâmica, com participações mais frequentes e elaboradas.

Por detrás da melhoria da autoestima dos alunos está, porventura, o estabelecimento explícito de um relacionamento afetivo e de confiança entre os participantes. Durante séculos, a concepção dualista do ser humano (razão/ emoção) renegou a dimensão afetiva para um plano inferior, excluindo-a da equação cognição, aprendizagem e construção do conhecimento (LEITE, 2006). Hoje, percebe-se que as relações afetivas ganharam um caráter fundamental, pois a transmissão do conhecimento implica, necessariamente, uma interação entre as pessoas. Por esta lógica, a relação educador(a)-educando(a) é uma relação interpessoal, o que implica a presença de afetos. A qualidade dessa relação influencia inevitavelmente a qualidade do processo ensino-aprendizagem, podendo ou não determinar o êxito de seus subseqüentes resultados.

Vygotsky (1985) identificou em sua abordagem dialética que o intelecto e o afeto têm regularidades internas que pedem um funcionamento integrado. Perder essa integração ou dividir essa unidade em seus elementos significa perder as propriedades inerentes ao todo. Assim, não há motivação sem pensamento, assim como é impossível um pensamento não motivado. Então, há que conhecer quais as dinâmicas que, na relação professor (moderador) e aluno, movimentam o processo de aprendizagem. Isso implica olhar o processo interativo na história de sua construção, compreendendo como se movimenta a dinâmica da unidade cognição e do afeto. 
O presente estudo mostrou que, ao promover a pedagogia da afetividade, a pesquisadora logrou cativar os alunos a participar com confiança, num ambiente educativo seguro e enriquecedor, o que poderá ter impactado sua autoconfiança. Como Paulo Freire (1983, p. 54) tão bem explicou, "nenhum deles [professor] passa pelos alunos sem deixar sua marca."

\subsection{Impacto da intervenção sobre criatividade}

Uma intervenção de índole dialógica e filosófica é notoriamente eficaz no desenvolvimento da criatividade. Porém, os dados deste estudo não conseguiram reiterar esse fato. Acredita-se que o instrumento de medição utilizado, aliado à curta duração do projeto, tenham contribuído para esse resultado díspar.

A comparação dos textos criativos produzidos pelos alunos na pré e na pós-avaliação mostrou um decréscimo na "produção criativa" da esmagadora maioria dos participantes. Alguns alunos que haviam produzidos 15, 9 e 8 linhas de texto criativo na pré-avaliação, na pós-avaliação desceram para 12, 7 e 5 linhas. A grande maioria que havia redigido, por exemplo, 14, 11, 10, 6 e 5 linhas na pré-avaliação, escreveu 5, 2, 1 linhas na avaliação final. Na pós-avaliação, todos os alunos produziram textos mais pobres, pouco estruturados, alguns sem detalhes, lógica ou interesse. É de salientar que o primeiro texto estudado na intervenção, "O urso que falava", incluiu as palavras oferecidas na escrita do texto criativo - floresta, caçador e urso. Na pré-avaliação, ninguém conhecia o texto, porém, todos os alunos escreveram mais do que na pós-avaliação, depois de todos terem debatido o texto.

Analisemos o que pôde influenciar a criatividade. Para ser criativo individualmente, deve existir motivação de criar, que pode ser intrínseca ou extrínseca. Como explica Sternberg (2000), motivação intrínseca é interna ao individuo e pode estar ligada ao prazer e ao desejo pessoal de fazer algo, enquanto que motivação extrínseca é externa ao individuo e pode ser inibidora da criatividade por estar muito referida ao meio e às expectativas externas. 0 processo criativo é ainda composto por dois elementos, domínio e campo. 0 domínio é composto do conhecimento existente de uma determinada área do empreendimento criativo, como pintura ou escrita criativa. Já o campo é formado pelo contexto 
social que cerca a criatividade.

É possível que dois fatores tenham contribuído para o aparente declínio da produção criativa dos alunos. Primeiro, a pós-avaliação não foi realizada pela pesquisadora principal, mas sim, pelas professoras da turma em sala de aula, logo, num contexto diferente daquela da intervenção, o que pode ter sido um elemento de desmotivação intrínseca para os alunos. Segundo, o fato de a avaliação final ter sido realizada nos últimos dias do ano letivo, quando os alunos já haviam terminado as aulas, provas e demais tarefas escolares, pode ter gerado uma menor expectativa por parte dos alunos e maior desinteresse em continuar a contribuir para a intervenção.

Acredita-se que, havendo futuras oportunidades de implementação deste estudo por período de tempo contínuo e mais alongado, poderá ser possível observar melhorias significativas na capacidade criativa dos participantes.

4.5 Processo metacognitivo e sua importância para o aprender a pensar bem

O estudo aqui apresentado fez uso da ficha de avaliação no final de cada sessão, fomentando a reflexão e a auto-avaliação dos alunos a fim de aprimorar o seu desempenho. Essa reflexão propositada permitiu que os alunos monitorassem o andamento das atividades e reajustassem a sua conduta e participação. Foi possível verificar que nas últimas sessões todos os alunos de ambos os grupos registraram reflexões mais elaboradas e ponderadas, tendo claramente apreendido o objetivo da tarefa.

Em adição, no final da intervenção, todos os alunos tiveram a oportunidade de refletir sobre as sessões e de registrar sua opinião sobre a importância que a intervenção tinha tido para eles. Os resultados foram tanto positivos como significativos. Apesar do curto tempo de exposição ao debate filosófico, todos os alunos consideraram a experiência valiosa, interessante e sentiram que tinham aprendido muitas coisas importantes, como explicaram alguns deles:

“Aprendi que você tem que tratar os outros como gosta de ser tratado."

"Aprendi muitas coisas que vou lembrar quando eu for adulta." 
"Achei bem legal, porque a gente discute e cada um sabe sobre a opinião do outro, os desejos, as opiniões e o que acha legal ou o que acha chato."

"Boas [as sessões], porque todas ensinavam alguma coisa importante sobre a vida, sobre as coisas que acontecem no mundo."

"Aprendi coisas novas, os textos sempre tinham uma moral e com essa moral eu aprendi muitas coisas novas."

"Aprendi muitas coisas novas como, por exemplo, que não devemos subestimar as pessoas."

"Considero que aprendi elaborar mais as respostas porque eu não elaborava muito".

Todos os alunos participantes afirmaram que consideravam importante aprender a pensar, conforme exemplificado por alguns:

“É importante porque aí você pensa antes de falar e não pensa bobeira na sua cabeça, você pensa os fatos e os junta e monta perguntas, por isso que é importante pensar bem antes de falar."

“É importante porque se você pensar ruim, acaba que não terá coisas boas."

"Sim, é importante porque pensando bem, nosso corpo fica bem. É que nem o ditado: "Mente sã, corpo são."

“É importante, pois antes de aprender, nós temos que pensar no assunto."

"Sim, [é importante] para nós podermos ter noção das coisas."

A importância da metacognição, ou pensar sobre o pensar, está amplamente documentada. Jou (2001) observou que crianças envolvidas numa intervenção sobre leitura compreensiva aumentaram seu conhecimento sobre a estrutura do texto e sobre suas capacidades metacognitivas, após a utilização de estratégias metacognitivas na forma de questionários. Flavell (1987) esclareceu que a experiência metacognitiva está relacionada à experiência subjetiva do 
indivíduo no que diz respeito a um determinado evento cognitivo. Assim, sentir que não entendeu um texto lido, ou não lembrar uma palavra simples ou ainda ter o sentimento de que se sabe algo seriam experiências metacognitivas. Segundo o autor, crianças pequenas podem ter tais experiências, mas não sabem interpretá-las. Com o desenvolvimento, porém, as crianças tomam consciência do que essas experiências significam e quais seriam suas implicações para o comportamento.

Afinal, a intervenção aqui delineada representou uma oportunidade para os alunos discutirem em conjunto, de forma estruturada e orientada, temas majoritariamente ligados a valores de cidadania. Debater deliberadamente conceitos como responsabilidade, respeito pelo próximo, confiança, liberdade, permitiu que os alunos tirassem suas próprias ilações e que se reposicionassem perante situações que, por exemplo, indicavam comportamento escolar e social inadequado ou problemático. Essa reflexão intencional pode ter contribuído para a mudança de atitude disciplinar observada nos alunos.

Ressalta-se ainda que o interesse desta pesquisa pela opinião dos participantes sobre "aprender a pensar bem" justifica-se pela limitação de tempo da intervenção. O programa que inspirou este estudo, FPC, interessa-se efetivamente pelo "pensar bem", algo que é desenvolvido ao longo de um período de grande investimento de tempo e esforço. Dado o tempo disponível para este estudo, não se vislumbrou grande impacto na componente cognitiva dos participantes, ou que o impacto fosse significativo o suficiente para ser discutido. Assim, operou-se de forma metacognitiva, buscando-se obter os posicionamentos dos alunos sobre a questão proposta.

\section{NOTAS FINAIS}

Durante sessões de discussão filosófica, os alunos podem ficar expostos a incontáveis perguntas e poucas respostas, que nem sempre são os objetivos finais da investigação do grupo. Logo fica claro que, perante uma infinidade de questões filosóficas, o importante é ajuizar e pesar todas as considerações de forma justa e protetora da integridade intelectual de todos os participantes. A estratégia educativa aplicada na comunidade de investigação, entendida por alguns autores como pedagogia da afetividade, facilita o processo ensino-apren- 
dizagem. Estudos mostram que uma abordagem filosófica conduz a melhoras da habilidade e aproveitamento escolar dos alunos, bem como mudanças positivas na interação dos alunos em sala de aula (TOPPING; TRICKEY, 2007).

Historicamente, a intervenção de índole filosófica tem servido a uma agenda educacional progressiva, vista como crucial na preparação de crianças para a cidadania numa sociedade democrática, inteiramente focada no diálogo. Além disso, uma abordagem pedagógica centrada no diálogo filosófico da comunidade de investigação promove o desenvolvimento social por meio de sua aplicação regular (uma hora por semana) e contínua (durante todo o ano letivo) (DANIEL; SCHLEIFER, 2008). Apesar do reduzido tempo disponível à intervenção, os dados obtidos pelo presente estudo permitiram corroborar o que outros já haviam demonstrado: o debate dialógico e filosófico teve um impacto geral positivo nos alunos participantes e foi possível observar melhorias nos parâmetros centrais do estudo, conforme explicado neste artigo. Parece ser lícito afirmar que, se foi possível observar melhorias em alunos expostos ao programa após um curto período de tempo, poderá ser possível antever um maior aproveitamento e impacto com a implementação desse programa por períodos de tempo ininterruptos mais extensos.

É comum entender a escola como uma preparação para a vida adulta, um espaço onde o respeito mútuo entre iguais permite a construção de normas de vivência. Essa co-construção de normas favorece a criação de um clima de cidadania e deveria permitir tanto ao professor como aos alunos administrar e resolver diferentes problemas de comportamento. Deveria servir de exemplo para a vida além dos muros da escola.

É do contraponto de ideias, desse momento de concepção coletiva e progressiva do saber gerado pelo debate, que nascem as novas descobertas e surge a evolução intelectual. Então, parece seguro afirmar que o papel da discussão e do debate, ferramentas poderosas para a construção da socialização e do pensamento, deveriam assumir um lugar mais preponderante na sala de aula.

O ensino contemporâneo deve almejar formar indivíduos autônomos e destros cognitivamente e, para tal, deve assumir a inquirição e a discussão como elementos vitais do processo ensino-aprendizagem. Em muitos países, a comunidade de investigação é um método adaptado ao ensino de tópicos como literatura infantil e cidadania. É uma técnica de ensino que permite a construção cooperativa do conhecimento. Uma comunidade de investigação oferece aos 
alunos a oportunidade de explorar e expandir em conjunto as suas próprias inquirições e interesses. Gera também uma situação pedagógica que convida e ensina os participantes a levantar questões, a ouvir e falar ponderadamente, a aceitar e respeitar diferentes opiniões, permitindo ainda a mudança de opinião e o uso de inúmeras habilidades do pensamento.

\section{REFERÊNCIAS}

AAMODT, A.M. Ethnography and Epistemology: Generating Nursing Knowledge. In: MORSE, J.M. Qualitative nursing research: a contemporary issue. Newbury Parke: Sage, 1991.

BERBEL, N.A. A problematização e a aprendizagem baseada em problemas: diferentes termos ou diferentes caminhos? Interface: Comunicação, Saúde e Educaçã, Botucatu, v. 1, n.2, 1998.

BARROW, W. Dialogic, participation and the potential for Philosophy for Children. Thinking Skills and Creativity, v. 5, p. 61-69, 2010.

BAUMEISTER, R.F. et al. Does high self-esteem cause better performance, interpersonal success, happiness, or healthier lifestyles? Psychological Science in the Public Interest, v. 4, n. 1, p. 1-44, 2003.

BRANCO, A. U.; VALSINER, J. Changing methodologies: A co-constructivist study of goal orientation in social interaction. Psychology and Developing Societies, v.9, p. 35-64, 1997.

CARIA, T. A cultura profissional dos professores: o uso do conhecimento em contexto na conjuntura da reforma educativa dos anos 90. Lisboa: Fundação Calouste Gulbenkian, 2000.

DANIEL, M. F. A filosofia e as crianças. São Paulo: Nova Alexandria, 2000.

DANIEL, M.F.; SCHLEIFER, M. A aprendizagem do dialogar e a prevenção primária da violência. In: C. LELEUX (Ed.), Filosofia para crianças: o modelo de Matthew Lipman em discussão. São Paulo: Artmed, 2008. p. 249-264.

DELORS, J. (Org.). Educação, um tesouro a descobrir. Relatório para a UNESCO da Comissão Internacional sobre a Educação para o século XXI. Porto: ASA, 1996.

DEWEY, J. Experience and education. New York: Collier Books, 1963.

FLAVELL, J. H. Speculation about the nature and development of metacognition. In: WEINERT, F.; R. KLUWE (Ed.), Metacognition, motivation, and understanding. Hillsdale, NJ: Lawrence Erlbaum, 1987. p. 21-29.

FREIRE, P. Pedagogia do oprimido. Rio de Janeiro: Paz e Terra, 1970.

FREIRE, P. Educação e mudança. São Paulo: Paz e Terra, 1983. 
GLASERSFELD, E.V. Construtivismo: Aspectos Introdutórios. In: CATHERINE, F. (Org. ), Construtivismo: teorias, perspectivas e prática pedagógica. Porto Alegre: Artmed, p. 19-24, 1998.

JOU, G.I. As habilidades cognitivas na compreensão da leitura: Um processo de intervenção no contexto escolar. 2001. Tese (Doutorado)-Pós-Graduação em Psicologia do Desenvolvimento, Universidade Federal do Rio Grande do Sul, Porto Alegre, RS. 2001.

LEITE, S. (Org.). Afetividade e práticas pedagógicas. São Paulo: Casa do Psicólogo, 2006.

LELEUX, C. (Ed.). Filosofia para crianças: o modelo de Matthew Lipman em discussão. São Paulo: Artmed, 2008.

LIPMAN, M.; SHARP, A.M.; OSCANYAN, F. Philosophy in the classroom. Philadelphia: Temple University Press, 1980.

LIPMAN, M. Do elementary school children need philosophy? In: REED, R.F.; JOHNSON, T.W. (Ed.). Philosophical documents in education. New York: Longman, 1994. p. 207-212.

LIPMAN, M. Critical thinking - what can it be? In: ORNSTEIN, A.; BECHAR, L. (Ed.), Contemporary issues in curriculum. Boston, MA: Allyn \& Bacon, 1995. p. 145-152.

LIPMAN, M. Teaching Students to Think Reasonably: Some Findings of the Philosophy for Children Program. The Clearing House, v. 71, n. 5, p. 277-280, 1998.

LIPMAN, M. A life teaching thinking. Montclair State University, NJ: Institute for the Advancement of Philosophy for Children, 2008.

LOEBER, R. et al. A.. The development of male offending: key findings from the first decade of the Pittsburgh Youth Study. Studies in Crime and Crime Prevention, v.7, 141-172, 1998.

MAINES, B.; ROBINSON, G. B/G STEEM: a Self Esteem Scale with Locus of Control Items. Bristol: Lucky Duck Enterprises, 1988.

MEAD, G.H. Mind, self and society: from the standpoint of a social behaviorist. Chicago: University of Chicago Press. 1972.

MYERS, D.G.; DIENER, E. Who is happy? Psychological Science, v. 6, p. 10-19, 1995.

PARRAT-DAYAN, S. A discussão como ferramenta para o processo de socialização e para a construção do pensamento. Educação em Revista, Belo Horizonte, v. 45, p. 13-23, 2007.

PHILPOT, V.; HOLLIMAN, W.; MADONNA, S. Self-statements, locus of control, 
and depression in predicting self-esteem. Psychological Reports, v. 76, p. 1007-1010, 1995.

ROTTER, J. B. Internal versus external control of reinforcement: a case history of a variable. American Psychologist, v. 45, 489-493, 1990.

SPENCER, S., JOSEPHS, R.; STEELE, C. Low self-esteem: the uphill struggle for self-integrity. In: BAUMEISTER, R. (Ed.). Self-esteem: the puzzle of low self-regard. NY: Plenum Press, 1993. p. 21-36.

STERNBERG, R.J. Psicologia cognitiva. Porto Alegre: Artmed, 2000.

TICE, D. The social motivations of people with low self-esteem. In: BAUMEISTER, R. (Ed.). Self-esteem: the puzzle of low self-regard. New York: Plenum Press,1993. p. 37-53.,

TOPPING, K.J.; TRICKEY, S. Collaborative philosophical inquiry for school-children: Cognitive gains at 2-year follow-up. British Journal of Educational Psychology, v. 77, p. 787-796, 2007.

VYGOTSKY, L. S. Thought and language. Cambridge, MA: The M.I.T. Press, 1985. 